Portland State University

PDXScholar

1990

\title{
Prediction of posttreatment level of functioning from performance in a leveled token economy for emotionally disturbed adolescents
}

Peter Arden Scott Grover

Portland State University

Follow this and additional works at: https://pdxscholar.library.pdx.edu/open_access_etds

Part of the Psychology Commons

Let us know how access to this document benefits you.

\section{Recommended Citation}

Grover, Peter Arden Scott, "Prediction of posttreatment level of functioning from performance in a leveled token economy for emotionally disturbed adolescents" (1990). Dissertations and Theses. Paper 4083. https://doi.org/10.15760/etd.5967

This Thesis is brought to you for free and open access. It has been accepted for inclusion in Dissertations and Theses by an authorized administrator of PDXScholar. Please contact us if we can make this document more accessible: pdxscholar@pdx.edu. 
AN ABSTRACT OF THE THESIS OF Peter Arden Scott Grover for the Master of Science in Psychology presented May $24,1990$.

Tit 1e: Prediction of Posttreatment Level of Functioning from Performance in a Leveled Token Economy for Emotionally Disturbed Adolescents.

APPROYED BY THE MEMBERS OP THE THESIS COMMITTEE:

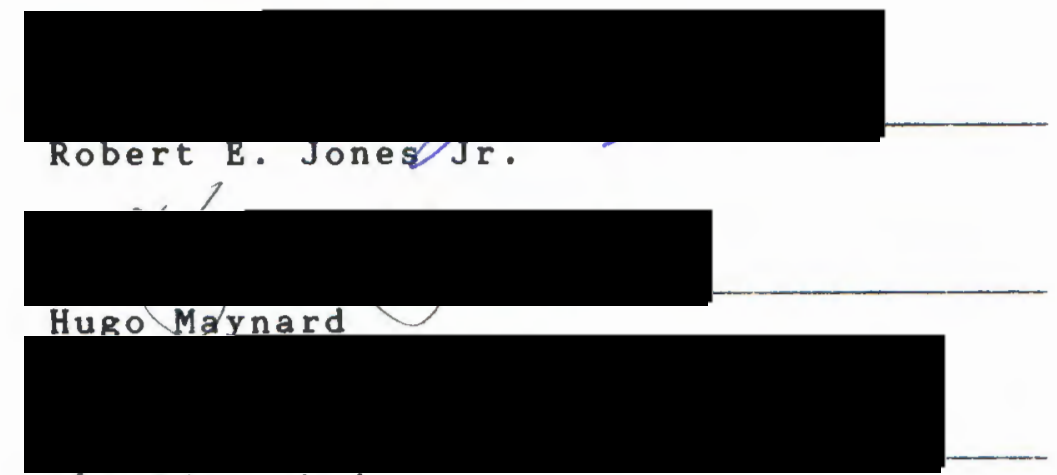

$$
\text { GeraldyGuthrie }
$$

This study examined the relationship between

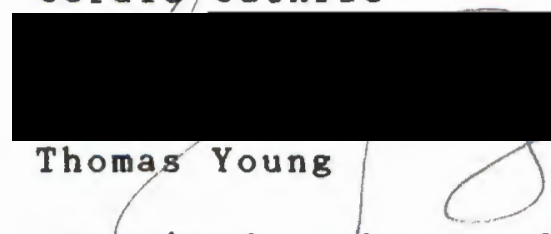
performance in a leveled token economy for emotionally disturbed adolescents and posttreatment level of functioning six months after discharge from the target program. The target program for the study is an acute care psychiatric hospital which specialized in the treatment of adolescents with both emotional and substance abuse problems. Previous literature on the outcome of token economy treatment 
programs for adolescents have generally been favorable however they have typically not examined level of functioning as an outcome criteria.

Questionnaires requesting information regarding the posttreatment level of functioning were sent to all of the adolescents patients discharged from the target program during a given three month period of time. A separate questionnaire was also sent to the former patient's legal guardian to obtain corroborating data. Data from returned Questionnaires was used to assign a global assessment of functioning level for each responding subject. Patient charts were reviewed to determine the pretreatment level of functioning and average daily token economy level attained by each subject.

Multiple regression analysis was performed on the data to determine the relationship between token economy performance and posttreatment level of functioning with the effect of pretreatment level of functioning removed. No significant relationships were found between any of the variables. The means for pretreatment level of functioning, token economy performance length of stay in the treatment program and age were compared for the responding and nonresponding subjects. No significant differences were found between the two groups on those four variables.

Continued research is suggested to clarify the above findings. Studies which examine the relationship between a 
number of within treatment variables and posttreatment level of functioning are suggested. Degree of follow through with suggested token economy programs within the home after discharge is also suggested as a variable which may affect posttreatment level of functioning. Pinally, more careful comparison of subjects who provided follow-up data with those who did not is suggested to insure that the results reported are not skewed by a sampling bias. 
PREDICTION OP POSTTREATMENT LEVEL OF FUNCTIONING PROM PERPORMANCE IN A LEVELED TOKEN ECONOMY FOR EMOTIONALLY DISTURBED ADOLESCENTS

by

PETER ARDEN SCOTT GROVER

A thesis submitted in partial fulfillment of the requirements for the degree of

\author{
MASTER OF SCIENCE \\ in \\ PSYCHOLOGY
}

Portland State University
1990 
TO THE OFFICE OF GRADUATE STUDIES:

The members of the Committee approve the thesis of Peter Arden Scott Grover presented May 4, 1990.

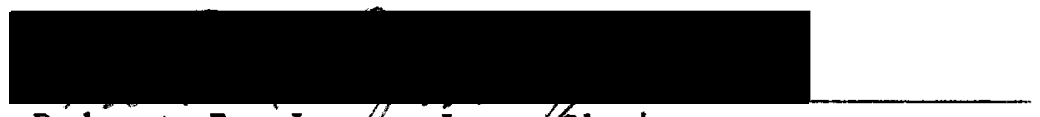

Robert E. Jongs Jr., Chair
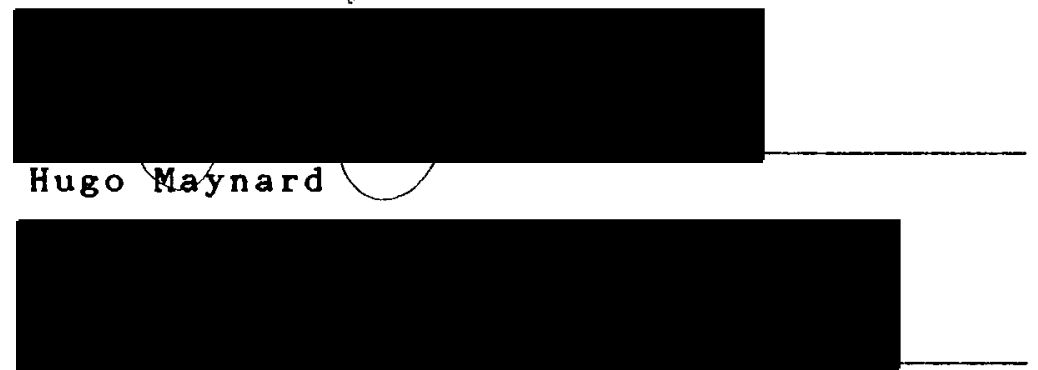

Gerald Guthrie

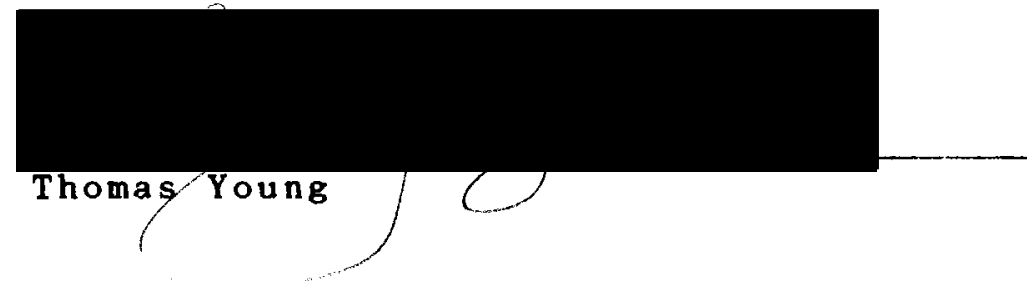

APPROVED:

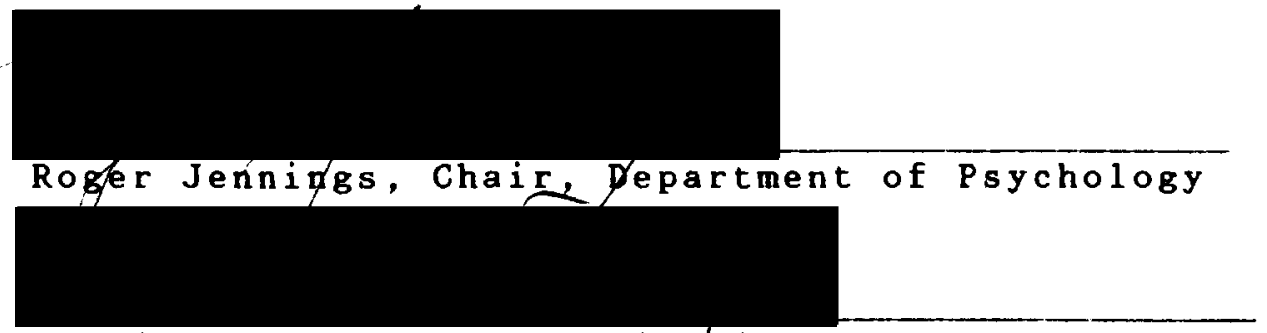

C. Hilliam Savery, Interimfice Provost for

Graduate Studies and Research 
TABLE OP CONTENTS

PAGE

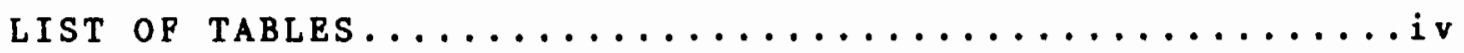

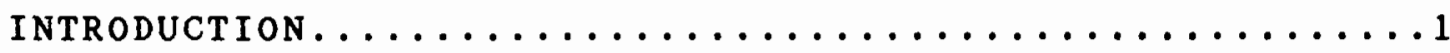

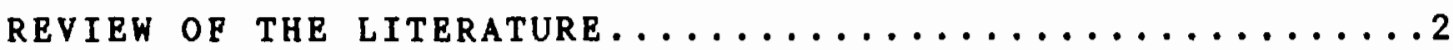

Token Economies........................

Outcome Evaluation Literature.............

Global Assessment of Functioning Scale..........

Program Participation Literature............11

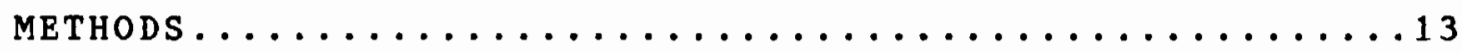

Description of the Target Program............13

subjects.........................

Procedure.........................

Measures.........................

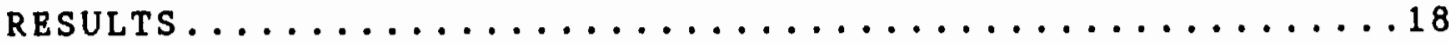

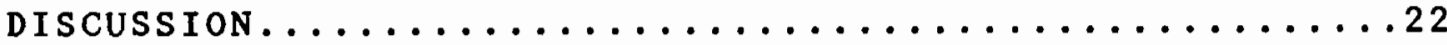

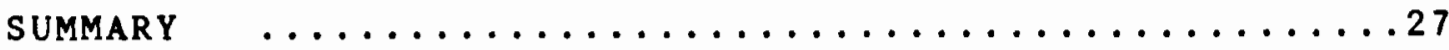

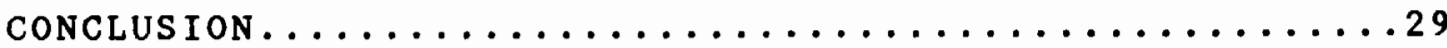

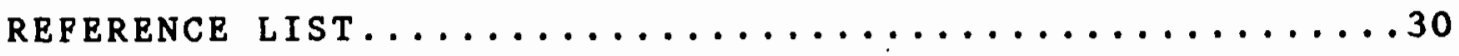
APPENDICES

A Sample mailing to subjects...............

B Sample mailing to guardians $\ldots \ldots \ldots \ldots \ldots \ldots$ 


\section{LIST OP TABLES}

TABLE

PAGE

I Variance in Posttreatment Gaf Scores

accounted for by Dependent Measures.........19

I Comparison Between Responding and

Nonresponding Subjects Using Several

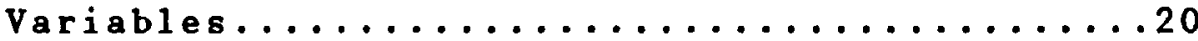

II Correlation Matrix of Variables Calculated

for the Responding Subsample.............21 


\section{INTRODUCTION}

This thesis is a study of the relationship between patient performance within a leveled token economy system in

a hospital based treatment program for adolescents (ages 1218) and level of patient functioning six months after discharge from the program. The target program specializes in the treatment of adolescents diagnosed with both a major psychiatric disorder (DSM III-R axis $I$ disorder) and a substance abuse disorder. Due to the specialized nature of this study and the subject program the introduction to this thesis project draws on literature from a variety of specialized areas. Por the sake of clarity each body of literature relevant to this study will be discussed in turn, followed by a description of the study and presentation of the results of the study. 


\section{REVIEW OF THE LITERATURE}

\section{TOKEN ECONOMIES}

One of the first documented applications of a token economy was the one developed and evaluated by Aylion and Azrin (1965, 1968) for chronic psychiatric patients. It was the goal of Ayllon and Azrin to apply the principles of operant conditioning described by Skinner (1938) to the task of modifying the behavior of chronic psychiatric patients. The token economy served the function of providing a schedule of regular reinforcement for specifically defined target behaviors. This program targeted adaptive and prosocial behaviors such as attending activities, engaging in self-care behaviors and engaging in social activities. Actual tokens were given to the patients when they displayed the target behaviors and the tokens could be exchanged for reinforcers such as special meals and special social activities.

The model token economy program for delinquent adolescents was developed at Achievement Place (Phillips, 1968). In the Achievement Place program points were awarded for targeted social, self-care and academic behaviors. Points were given immediately following the targeted 
behaviors and tallied on a card carried by each resident. Points were lost or subtracted (fines) for specified inappropriate behaviors. Points could be exchanged for various special privileges such as an allowance, snacks and late bedtime. This system had different stages of administration in that the residents moved from a daily, to a weekly, and then to a merit system. In the merit system the residents did not receive points but were given certain privileges as long as they maintained specified responsibilities. This gradual progression from a clearly defined system of reinforcement to a more real world system of reinforcement was designed to encourage the generalization of the target behaviors to settings outside of the initial token economy. In 1981 token economies based on the Achievement Place model were being used at approximately 150 group homes for delinquent adolescent throughout the United States (Jones, Weinrott, \& Howard, $1981)$.

The developers of the Achievement Place program published a few evaluative articles (e.g. Phillips, 1968; Phillips, Phillips, Fixsen, \& Wolf, 1971). However, there has been practically no evaluative research performed on these types of programs in recent years. Since 1971 the use of programs based on the Achievement Place model have become an integral part of many treatment programs for delinquent and emotionally disturbed adolescents. The nature of the 
token economies in these treatment programs has evolved without continued documentation in the academic literature. Specifically, many treatment centers for delinquent and emotionally disturbed adolescents now employ some form of token economy with a hierarchical level system. In a leveled token economy, points (rarely actual tokens) are earned for target behaviors. After the accumulation of a specified number of points, or the maintenance of a daily or weekly point average, the client graduates to a higher level in the token economy system. Reinforcers come as clusters of increased privileges that are earned with each increase in leve1. It is this type of multi-leveled token economy that is utilized in the adolescent treatment program that is the target program for the current study.

There is a surprising lack of literature which describes any theoretical framework for the hierarchical type of token economy described above. A review of the literature revealed only one paper on the subject (Klotz, 1987). The program developed by Klotz is utilized in a school for emotionally disturbed adolescents. Students are given a score of one, two or zerobased on their ability to display a number of target behaviors such as "on task" behavior, appropriate socialization and not encouraging peers displaying inappropriate behaviors. Accumulation of points allows the student to graduate through a series of levels. The levels offer groups of increased privileges and 
less restrictive supervision culminating in graduation from the token economy to a merit system. The system is designed to provide the safety and supervision required for students who display a number of maladaptive behaviors at the lower levels, as well as encouraging the generalization of appropriate behaviors without the structure of the token economy at the higher levels. Unfortunately, Klotz cited only a review of token economies by Kazdin (1982) which calls for client preselection of backup reinforcers, staff training and gradual removal of the token economy to encourage generalization of the target behaviors. No specific rationale is given for the level system and the clusters of privileges which serve as reinforcers.

The program designed by Klotz (1987) is very similar to the token economy employed in the target program for the current study in that it offers a maximum of safety and supervision, combined with minimum of privileges, at the lower levels and a less restrictive environment with greater access to privileges at the highest level. The target program also defines specific target behaviors and tasks which must be completed to progress from level to level. The current study seeks to provide some empirical data on the effectiveness of the leveled token economy system. It is hoped that it will both contribute to the evolution of the token economy literature and stimulate further research in the area. 
Previous evaluations of the therapeutic outcome of token economies have generally been favorable. The evaluation of Achievement Place is the most relevant to the current study (Kirigin, Wolf, Braukmann, Pixsen, Phillips, 1979). Kirigin et al. (1979) demonstrated a significantly lower rate (approximately one half) of reinstitutionalization, and a significantly higher rate of school attendance among Achievement Place residents when compared to youths who were placed in a traditional detention setting. Bvaluation of the behavioral management program developed by Klotz (1987) showed that 71 percent of the students progressed one or more levels and/or maintained their baseline placement in one of the two highest levels. However, no posttreatment follow-up data was reported in the study by Klotz (1987).

\section{OUTCOME EVALUATION LITERATURE}

The mental health program evaluation literature covers a wide variety of programs. Literature concerning psychotherapy outcome was not informative in terms of the methodology of the current study primarily because of the types of subjects with which it is concerned. The subjects of psychotherapy outcome studies are generally outpatients. The subjects of the present study, however, are inpatients whose hospitalizations are generally precipitated by behavior which endangers the immediate safety of themselves 
or others. As a result, it is ethically and practically difficult to utilize a control group in the study of this type of inpatient population. In fact, the use of control groups is controversial even within the outpatient psychotherapy outcome literature. Basham (1986) discusses the ethical and practical difficulties of control groups in psychotherapy outcome studies. Basham states that it is ethically impractical to randomly assign clients who request some type of care to treatment and no treatment control groups. Control groups that can be created following ethical considerations are difficult to compare. As an alternative Basham proposes studies which examine the comparative outcomes of different types of treatments. The current study was designed so that the data gathered for it could be compared with outcome and program evaluation data from similar treatment programs.

Another body of program evaluation literature deals with inpatient psychiatric hospitals. This literature is also difficult to apply to the current study because of differences in the subject populations. The subjects of inpatient psychiatric hospital studies are generally chronic schizophrenic adults. The primary outcome measure employed in these studies is rates of rehospitalization. The sole measure of rehospitalization rate is appropriate for a population that is not expected to return to optimal social and occupational functioning. In contrast, literature 
concerning outcome and methodological strategies for evaluating substance abuse treatment programs and residential care centers for emotionally disturbed and delinquent adolescents provide information which applies directly to the current study. The substance abuse treatment and adolescent residential treatment 1 iterature is highly useful because it describes the use of rehospitalization and recidivism measures as well as the use of symptom, social functioning and occupational (or school) functioning measures as indicators of outcome.

Sobel1, Brochu, Sobel1, Roy, \& Stevens (1987) reviewed the quality of outcome evaluation methodology for all alcohol treatment evaluations published between the years 1980 and 1984. They noted the following methodological shortcomings in a number of the studies that they reviewed: (1) insufficient reporting of subject background and drinking history variables; (2) inadequate description of the treatment provided; ( 3 ) failure to gather pretreatment data for variables assessed in follow-up, and failure to examine possible pretreatment differences among treatment groups; (4) drawing conclusions in the absence of any statistical analysis, or the inappropriate use of statistics; and (5) failure to quantitatively assess drinking behavior (Sobel1 et a1., 1987). An attempt has been made to incorporate all of these considerations into the current study. The details of how this is accomplished 
is included in the methods section of the current study. In another review of alcohol treatment evaluation literature Miller (1986) makes the following recommendations for alcohol treatment outcome methodology and reporting of results: (1) a clear description of how the diagnosis (of alcoholism) was made; (2) use of corroborating data to verify patient reports; (3) reporting evidence of positive changes in psychosocial and economic adaptation as well as improvement in drinking behavior; and (4) consideration of the use of drugs other than alcohol. These recommendations have also been considered in the design of the current study.

Whittaker, Overstreet, Grasso, Tripodi\& Boylon (1988) recommend multiple indicators of success in the evaluation of residential youth care and treatment. They also state that specifying the differential levels of risk at intake and specifying the nature of the treatment procedures are important parts of a thorough outcome study.

\section{GLOBAL ASSESSMENT OF PUNCTIONING SCALE}

In their discussion of the development of a scale to measure outcome of the treatment of emotionally disturbed adolescents Jackson, Olsen, Schafer \& Holmes (1986) note that "adolescents are often faced with multiple problems and a history of complex family trouble. They also note the lack of an instrument which can measure the adolescent's 
ability to function in all the relevant interactions with others that occur in his or her daily life. They state that the use of level of functioning scales which are based on behavioral objective descriptors in outcome evaluations would improve the utility of outcome studies and the ability to compare these studies with one another. They cite the Global Assessment Scale or GAF (Endicott \& Spitzer, 1976) as one such measure. Although Jackson et. al. (1986) are critical of some of the shortcomings of the GAF (and offer their own scale as more complete), I have utilized the GAP in the current study since it is a well researched instrument and is incorporated into the DSM-III-R diagnostic system. In the multiaxial diagnostic system outlined in the DSM-III-R, axis $V$ is an estimate of the highest GAP in the last year and the GAF at the time of admission. The GAF allows for the consolidation of multiple measures of client functioning before and after treatment. This consolidation simplifies the statistical analysis of the data, allows for the classification of clients by level of pretreatment functioning called for by the above cited authors and allows for comparison with other studies. Related studies can be compared with the current study as long as they utilize the GAF or the data gathered for them are complete enough to assign a GAP level to subjects in the study. 


\section{PROGRAM PARTICIPATION LITERATURE}

One alcohol treatment evaluation (Bromet, Moos, Bliss \& Wuthmann, 1977) is similar in many ways to the current study and deserves special consideration. Bromet et al. examined the relationship between level of client participation in a variety of alcohol treatment programs and posttreatment functioning. Five different types of treatment programs were evaluated, one of which was an inpatient milieu therapy program which is similar in many ways to the target program. In the analysis of their data Bromet et a1. (1977) calculated the level of posttreatment functioning which could be predicted by pretreatment functioning. Improvement on any given posttreatment variable was only considered significant if it exceeded the level predicted by pretreatment functioning. The authors found that, for the milieu treatment program, participation was related to a significant improvement in three areas of posttreatment functioning: psychological, social and alcohol consumption.

The present study utilizes a methodology which is similar to the Bromet et. al. (1977) study in that the pretreatment level of the outcome measure is controlled for in the examination of the relationship between a within treatment variable and an outcome variable. Since a number of the target behaviors specified in the token economy in the subject program for the current study are related to 
participation in the program, the results of the Bromet et al. study allow me to make the following prediction about the results of the current study. In the current study better performance in the token economy should predict a level of posttreatment functioning higher than that predicted by pretreatment functioning. The null hypothesis for this thesis project is that the amount of variance in posttreatment level of functioning that can be uniquely accounted for by token economy performance will not significantly exceed the amount of variance in posttreatment level of functioning that can be accounted for by pretreatment level of functioning. 
METHODS

\section{DESCRIPTION OP THE TARGET PROGRAM}

The target program is housed in a sixty bed, free standing psychiatric hospital. It consists of a thirty bed unit for adolescents diagnosed with a major psychiatric diagnosis (DSM-III-R axis I) and a substance abuse disorder. Patients are admitted from throughout the region and are referred by state agencies, private psychologists, psychiatrists and the patient's parent.

Upon admission patients are given complete psychological, chemical dependency, and psychosocial assessments. Patients are also interviewed by an admitting psychiatrist. They are diagnosed on the basis of the interview with the psychiatrist and the above assessments.

Patients participate in a multimodal treatment program which consists of individual and group psychotherapy, chemical dependency groups which focus on education and introduction to twelve step programs (AA and NA), occupational and recreational therapy, a school program, family therapy and participation in a leveled token economy. The treatment staff consists of psychiatrists, psychologists, certified drug and alcohol counselors, 
occupational and recreational therapists, school teachers, psychiatric nurses and mental health therapists who have at least a bachelors degree in a social science and experience working with adolescents in a related setting.

\section{SUBJECTS}

Subjects were 73 patients between the ages of 11 and 18 admitted to a private for profit psychiatric/chemical dependency hospital. Inclusion criteria were: 1. need for intensive inpatient treatment as determined by the admitting physician; 2. diagnosis of a substance abuse and/or Axis I psychiatric disorder according to DSM-III-R criteria; 3. ability to pay for treatment, usually via third-party insurance; and 4. discharged within a specified time period six months before the mailing of an outcome data questionnaire. Three patients who met the above criteria were excluded because they were in the program for less than ten days.

Although some of the patients are admitted with their consent, a majority of the patients are admitted to the hospital under various degrees of coercion. As minors the subjects of the current study can be signed into the treatment program against their will by their parents or legal guardians. Some of the patients have been referred to the hospital by juvenile court authorities and have been 
court mandated to receive inpatient psychiatric/chemical dependency treatment.

Corroborating data regarding the former patients behavior six months after discharge was sought from the patients and from their current legal guardians.

The mean age of the patient subjects was 15.07 years $(S D=1.45) ; 57$ percent of the subjects were male and 43 percent were female. All subjects were under the age of eighteen.

PROCEDURE

A mailing, consisting of a cover letter from the treatment program director, a questionnaire designed to gather information regarding the patient's posttreatment level of functioning and appropriate consent forms, was sent to all subjects and their legal guardians. Separate questionnaires that were identical except for appropriate pronouns were provided for the subject and his or her legal guardian. Separate stamped return envelopes were provided for the subject and the guardian to encourage privacy and a candid response. Examples of items in the mailing are included in the appendix.

A consent form was attached to each questionnaire. The form for the subjects sought consent for their own participation in the study. The forms for the guardian 
sought consent for both themselves as a respondent and for the subject as a minor.

Pretreatment and within treatment data were gathered retrospectively by review of the patient chart. These data were gathered in an anonymous fashion therefore consent was not obtained for the gathering of these data.

Questionnaires and consent forms for 20 subjects were returned. The total sample size was 73 , the nonresponding subject sample size was 53 and the responding sample size was 20 .

\section{MEASURES}

Data for pretreatment level of functioning were obtained by retrospective chart review. The psychiatrist admission summary, psychosocial assessment and chemical dependency assessment were reviewed. This information was used to complete a worksheet which tabulated information regarding level of functioning in the areas of school, work, legal involvement, family functioning, chemical use, mental status, danger to self and danger to others (see appendix for sample worksheet). The completed worksheet was used to assign a pretreatment level of functioning based on the Global Assessment Scale (Endicott, Spitzer, F1eiss et. al., $1976)$.

Patient charts were reviewed and the patients level within the token economy $(0,1,2,3$ or 4$)$ was noted. The 
average daily token economy level for all subjects was calculated.

A posttreatment level of functioning was assigned based on questionnaire data for subjects who returned questionnaires and consent forms. In sixteen cases questionnaires were returned by both the former patient and their legal guardian. In four cases the questionnaire was returned only by the legal guardian. The questionnaire requested information regarding functioning in the areas of work, school, legal involvement, substance use, family functioning, harm to self and harm to others. Subjects and their guardians were also asked to rate overall level of functioning on a ten point scale which used descriptors from the GAF (see appendix for sample questionnaires and consent forms).

Length of stay and age of the subjects was also recorded to assist in the comparison of responding and nonresponding subjects. 


\section{RESULTS}

Data were analyzed using SAS statistical software package on the Portland State University IBM mainframe computer. A hierarchical multiple regression analysis using two models for the posttreatment GAP scores was calculated. In the first model the amount of variance in the posttreatment GAP scores that could be accounted for by the pretreatment GAP scores alone was calculated. The R-square for this model was. 11. The P value for this result is 2.24 with 1 and 18 degrees of freedom. It is not significant at the .05 level of confidence.

In the second model the amount of variance in the posttreatment GAP scores that could be accounted for by the pretreatment GAF scores and the performance in the token economy was calculated. The R-square for this model was 15. The $F$ value for this result is 1.5 with 2 and 17 degrees of freedom. It is not significant at the .05 leve1. Since this model was not significant it was clear that the increment in the variance of the posttreatment GAF scores that could be accounted for by token economy performance with the effect of pretreatment functioning removed would also not be significant. These results are summarized below in Table I. 
TABLE I

VARIANCE IN POSTTREATMENT GAP SCORES ACCOUNTED FOR BY DEPENDENT MEASURES

$$
\text { R-Square P Value df }
$$

Pretreatment GAF

2.24

1,18

Pretreatment GAF plus .15

1.50

2,17

Token Economy

Token Economy minus

Pretreatment GAF

$.04 \quad 8.0 \quad 1,17$

Mean scores for pretreatment GAF, token economy performance, length of stay and age between responding and nonresponding subjects were compared using $t$ tests. No significant differences were found at the .05 level on any of these measures between the nonresponding and responding groups of subjects. F tests showed no significant differences at the .05 level between the variances of the scores for pretreatment GAF, token economy performance, length of stay and age for the responding and nonresponding samples. The results of these p tests indicated that a standard $t$ test was an appropriate comparison for these scores. The results of the $t$ test comparisons are summarized below in Table II. 


\section{TABLE I I}

COMPARISON BETWEEN RESPONDING AND NONRESPONDING

SUBJECTS USING SEVERAL MEASURES

\begin{tabular}{|c|c|c|c|c|c|c|}
\hline & \multicolumn{2}{|c|}{ Responding } & \multicolumn{2}{|c|}{ Nonresponding } & & \\
\hline & mean & variance & mean & variance & $t$ & $\mathrm{df}$ \\
\hline $\begin{array}{l}\text { pretreatment } \\
\text { GAF }\end{array}$ & 3.60 & .62 & 3.62 & 1.29 & .07 & 71 \\
\hline $\begin{array}{l}\text { token } \\
\text { economy }\end{array}$ & .76 & .16 & .86 & .20 & .87 & 71 \\
\hline $\begin{array}{l}\text { length of } \\
\text { stay }\end{array}$ & 37.95 & 305.94 & 35.88 & 155.26 & .56 & \\
\hline $\operatorname{age}$ & 15.20 & 3.12 & 15.02 & 1.75 & .47 & \\
\hline
\end{tabular}

To determine if there was a significant difference between the mean pretreatment GAF score and the mean posttreatment GAF score for the responding sample a t test was calculated for the difference between these two means. The mean pretreatment GAF scores was 3.60 and the mean for the postereatment GAP scores was $6.25 \quad(t=2.65 ; \quad d f=17$; p(.0001). This result indicates that six months after treatment the average respondent is functioning at a level that is significantly higher than their level of functioning upon admission to the treatment program.

The correlation matrix of the experimental and descriptive variables for the responding subsample is 
reproduced in Table III to facilitate a more detailed discussion of the pattern of results obtained.

\section{TABLE I I I}

CORRELATION MATRIX OF VARIABLES CALCULATED POR THE RESPONDING SUBSAMPLE

\begin{tabular}{|c|c|c|c|c|}
\hline $\begin{array}{l}\text { Pretreatment } \\
\text { GAF }\end{array}$ & $\begin{array}{l}\text { Token } \\
\text { Economy } \\
.15\end{array}$ & $\begin{array}{l}\text { Posttreatment } \\
\text { GAF } \\
.33\end{array}$ & $\begin{array}{l}\text { Length } \\
\text { of Stay } \\
--.24\end{array}$ & $\begin{array}{l}\text { Age } \\
-.09\end{array}$ \\
\hline $\begin{array}{l}\text { Token } \\
\text { Economy }\end{array}$ & & -.14 & -.17 & .15 \\
\hline $\begin{array}{l}\text { Post treatment } \\
\text { GAF }\end{array}$ & & & -.33 & -.09 \\
\hline $\begin{array}{l}\text { Length } \\
\text { of Stay } \\
\text { None of } \\
\text { the .05 }\end{array}$ & $\begin{array}{l}\text { the above } \\
\text { level. }\end{array}$ & correlations achi & ed sign & -.17 \\
\hline
\end{tabular}




\section{DISCUSSION}

The pattern of the results of the regression analysis clearly indicate acceptance of the null hypothesis for the current study. Performance within the token economy did not account for a significant amount of variance in the posttreatment level of functioning beyond that accounted for by pretreatment level of functioning. The results of the t tests comparing responding and nonresponding subjects clearly indicate that this nonsignificant result is not the result of a biased sample of responding subjects.

The general pattern of relationships indicated by the correlation matrix is consistent with past findings in one important respect (Bromet et. a1., 1977; Armor, Polich, and Stambu1, 1976; Craft, Sheehan, Driggers, and Dubois, 1975). None of the correlations in the correlation matrix are significant however, the strongest relationship in the correlation matrix is that between pretreatment and posttreatment level of functioning. This reinforces the notion that it is important to control for pretreatment level of functioning when examining the significance of treatment effects. The second strongest relationship in the correlation matrix is the inverse relationship between pretreatment level of functioning and length of stay, 
followed closely by the inverse relationship between length of stay and posttreatment level of functioning. This pattern indicates that subjects who are more at risk for poor therapeutic outcome spend a longer period of time within the treatment program.

The above result is contradictory to the result obtained by Bromet et al. (1977) for adult patients involved in a milieu oriented inpatient alcohol treatment center. Specifically Bromet et a1. found a level of posttreatment functioning that was significantly higher than that predicted by pretreatment level of functioning across a number of variables for the milieu therapy subjects. There are some significant differences between the subjects of the current study and those in the Bromet et al. study which could account for these divergent findings. The first is that the subjects in the Bromet et al. study were adults with a primary presenting problem of alcohol dependence. In contrast, the subjects in the subject program of the current study are adolescents who typically present with a number of behavioral difficulties upon admission. The difference between the two subject populations is underscored by the fact that in the Bromet et al. study the subjects in the milieu therapy condition had the highest average level of functioning and socioeconomic economic status in their sample. Subjects in the Bromet et al. study who were in groups with a lower level of pretreatment functioning and 
socioeconomic status did not achieve a significantly higher level of posttreatment functioning.

Although data regarding socioeconomic status were not available in the present study, the subjects typically exhibited a marked impairment in level of functioning upon admission. As such they are substantially at risk for a continued decline in level of functioning. The mean pretreatment GAP on a ten point scale for the subjects in the present study was 3.6. This level of functioning indicates serious impairment in several areas of life. Por example, an average GAF level of 3.6 indicates that the typical patient admitted to the target program is failing in school, has multiple runaways from home, has multiple legal charges, engages in a pattern of heavy substance abuse and has made a recent suicide attempt. In terms of pretreatment level of functioning the subjects in the current study are more like the subjects in the Bromet et. al. study who did not show a significant increase in their posttreatment level of functioning.

In terms of learning theory there is another variable which may influence the relationship between performance in the treatment program token economy and posttreatment level of functioning. Patients are most often discharged to a setting which does not maintain the contingencies on their behavior which were present in the treatment program token economy. Family therapists at the target program often 
recommend a form of leveled token economy to be carried out within the patients home after discharge. Further research could examine the relationship between posttreatment level of functioning and the degree of follow through with the implementation of a leveled token economy in the patients postdischarge home setting.

It is clear from the comparison of the mean pretreatment and posttreatment GAF scores that an improvement in level of functioning does occur within six months after discharge. Given the results of the current study this improvement in level of functioning is not related to performance within the token economy. Further research should examine two important questions. The first is would this change in level of functioning occur without any treatment at all or with a different form of treatment. Control group or comparative outcome studies would help to answer this question. The second question is, are there other within treatment variables which are related to posttreatment level of functioning? The current study examined only one aspect of a multi-modal treatment program. A more in depth study would examine a number of within treatment variables and attempt to describe the relative relationship between each of them and posttreatment level of functioning.

It is possible that the significant improvement between pretreatment and posttreatment level of functioning is a 
function of some form of bias on the part of those persons who returned the posttreatment level of functioning questionnaire. It is possible that those who returned the questionnaire tended to be those persons who had a favorable experience with the treatment program. In future studies an instrument which measured satisfaction with the treatment program could be included in the data gathering and analysis to determine if a satisfaction bias served to exaggerate the observed difference between the mean pretreatment and posttreatment level of functioning scores.

It is important to note that within the context of the multimodal treatment strategy of the target program the leveled token economy system serves a number of important functions besides an attempt to influence positive patient outcome. For example, the token economy serves to encourage active patient participation in the variety of treatment activities offered within the program. It also provides the staff members with a means of monitoring the potential of patients to harm themselves or others and provides for a greater level of security and safety precautions for patients at risk for harming themselves or others. Therefore results which do not support the above hypotheses should not be interpreted as cause to remove the token economy as a treatment program component without careful evaluation of its other important functions. 


\section{SUMMARY}

The current study examined the relationship between performance in a leveled token economy and postreatment level of functioning six months after discharge from an acute care in patient treatment program which specializes in the treatment of adolescents with both a psychiatric disorder and a substance abuse disorder.

The development of the leveled token economy from the first applications of operant conditioning principles to chronic psychiatric patients to the wide spread use of leveled token economies in treatment programs for adolescents is reviewed. A review of literature concerning the methodology appropriate to the evaluation of both psychiatric and chemical dependency treatment programs is discussed.

Analysis of data which described the pretreatment level of functioning, performance within the leveled token economy and posttreatment level of functioning showed no significant relationship between performance in the token economy and posttreatment level of functioning.

A comparison between former patients who provided posttreatment level of functioning data and those who did 
not showed that there were no significant differences between these two groups on their mean scores for pretreatment level of functioning, performance in the token economy, length of hospital stay and age. 


\section{CONCLUSION}

It is apparent from the results of the current study that there is not a strong relationship between within treatment performance in a leveled token economy program and posttreatment level of functioning. It does however, seem that persons discharged from the target program of the current study do show an significant improvement between their pretreatment and posttreatment level of functioning. The reason for this difference is unclear. Since the target program uses multiple modes of treatment a comprehensive examination of all of the within treatment factors and their interactions is necessary to determine which aspects of the treatment program contribute to positive treatment outcome. Further methodological rigor is also necessary to insure that the observed improvement in level of functioning is not a result of a biased sample of subjects who provide posttreatment level of functioning data. 


\section{REFERENCE LIST}

American Psychiatric Association (1987). Diagnostic and Statistical Manual of Mental Disorders, Third Edition Revised. Washington D.C., American Psychiatric Association.

Ayllon, T., and Azrin, N. H. (1965). The measurement and reinforcement of behavior of psychotics. Journal of the Experimental Analysis of Behavior, 8, 356-383.

Basham, R. B . (1986). Scientific and practical advantages of comparative design in psychotherapy outcome research. Journal of Consulting and Clinical Psychology, 54, 88-94.

Bromet, E., Moos, R., B1iss, F. and Wuthmann, C. (1977). Posttreatment functioning of alcoholic patients: Its relation to program participation. Journal of Consulting and Clinical Psychology, 45, 829-842.

Endicott, J., Spitzer, R. L., Pleiss, J. L., and Cohen, J. (1976). The global assessment of functioning scale: A procedure for measuring overall severity of psychiatric disturbance. Archives of General Psychiatry, 33, 766771 .

Jones, R. R., Weinrott, M. R., and Howard, J.R. (1981). The National Evaluation of the Teaching-Pamily Model. Final report to the National Institute of Mental Health, Center for Studies in Crime and Delinquency.

Jackson, N., Olsen, L., Schafer, C. and Holmes, W. M. (1986). Evaluating the treatment of the emotionally disturbed adolescent. Social Work, 31, 182-185.

Kazdin, A. E. (1982). The token economy: A decade later. Journal of Applied Behavior Analysis, 15, 431-445.

Kirigin, K. A., Wolf, M. M., Braukmann, C. J., Pixen, D. L., and Phillips, E. L. (1966). Achievement Place: A preliminary outcome evaluation. In J. S. Stumphauer (Ed), Progress in Behavior Therapy with Delinquents. Springfield I11., Charles C. Thomas. 
Klotz, M. E. (1987). Development of a behavior management leve1 system: A comprehensive school-wide behavior management system for emotionally disturbed adolescents. The Pointer, 31, 5-11.

Miller, S. I. (1986). How to tell if alcoholism treatment has worked: Assessing outcome studies. Hospital and Community Psychiatry, 37, 555-556.

Phillips, B. L. (1968). Achievement place: Token reinforcement for "pre-delinquent" boys. Journal of Applied Behavior Analysis, 1, 213-223.

Phillips, E. L., Phillips, E. A., Pixsen, D. L., and Montrose, M, W, (1971). Achievement place: Modification of the behaviors of pre-delinquent boys within a token economy. Journal of Applied Behavior Analysis, 4, 45-59.

Sobe11, M. B., Brochu, S., Sobel1, L, C., Roy, J. and Stevens, J. A. (1987). Alcohol treatment outcome evaluation methodology: State of the art 1980-1984. Addictive Behaviors, $12,113-128$.

Whittaker, J, K., Overstreet, E. J., Grasso, A., Tripode, T. and Boylan, F. (1988). Multiple indicators of success in residential youth care and treatment. American Journal of Orthopsychiatry, 58, 143-147. 
APPENDIX A

SAMPLE OP MAILING TO SUBJECTS 


\section{Dear Family Member,}

We at Pacific Gateway Hospital are in the process of gathering information which will help us to evaluate and improve the quality of our treatment program. Your participation will help us very much and it will also help people who come to the hopital in the future.

You can help us do this by filling out the attached questionnaire and returning it to us in the enclosed stamped envelope. There is also a consent form for you to sign indicating that you agree to participate in the study.

Peter Grover is a student at Portland state University and is helping us to gather and process this information as part of his master thesis project. If you have any questions about the questionnaire or the evaluation study you may reach him by calling the hospital at (503)-234-5353.

All information that you give will be kept strictly confidential. Please do not put your name on the questionnaire as it will be separated from the consent form when you return it so that no one handling the information will know the names of the people who give it.

It is also important for us to get information from your son or daughter about how they are doing now. If you agree to let them participate please sign the attached consent form and give him/her the questionnaire provided. We have also provided a separate envelope for them to send in their questionnaire. Pleass allow them to complete the questionnaire in private so that they can feel comfortable being honest.

Thank you for your help.

sincerely,

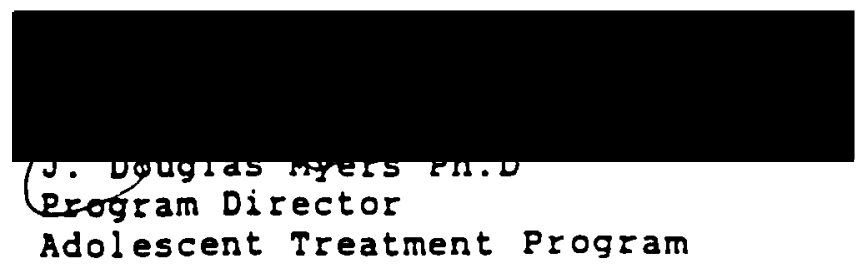




\section{INFORMED CONSENT}

Note: 2 consent forms are attached. Please sign and return one form with the questionnaire. Detach the other form and keep for your records.

I, , hereby agree to serve as a subject in the Pacific Gateway Hospital treatment program outcome study conducted by Peter Grover under the supervision of Dr. Meyers (Pacific Gateway Hospital) and Dr. Jones (Portland State University.) Your responses will be used by Peter Grover as data in a thesis for Portland State University's M.S. program in

Psychology.

I understand that the study involves filling out and returning the attached questionnaire.

I understand that by signing this consent form, I a m releasing information from my treatment records to Peter Grover for use as data in the above mentioned thesis.

Peter Grover agrees to answer any questions I may have about the study and what is expected of me. I bave been assured that all information I give will be kept confidential, and that the identity of all information used will remain anonymous.

I understand that the possible risks to me associated with this study are the inconvenience of fllling out the questionnaire and the possible discomfort associated with answering some of the questions.

I understand that the purpose of this study is to find out more about what happens to people after they leave the program so that we can find ways to improve the quality of the program.

I may not receive any direct benefit from participation in this study, but my participation may help to increase knowledge and benefit others in the future.

I understand that I am not required to be part of this study and that there will be no consequences if I do not participate.

I have read and understand the above information.

Date

Signature

If you experience problems that are the result of your participation in this study, or if you wish to verify university approval of this study, please contact the secretary of the Human Subjects Research and Review Comittee, Office of Grants and Contracts, 303 Cramer Hall, Portland State University, 464-3417. 


\section{IX) NOT PUT YOUIR NAMIL ON THIS PAIPBR

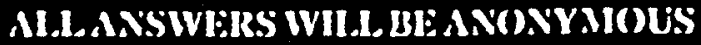

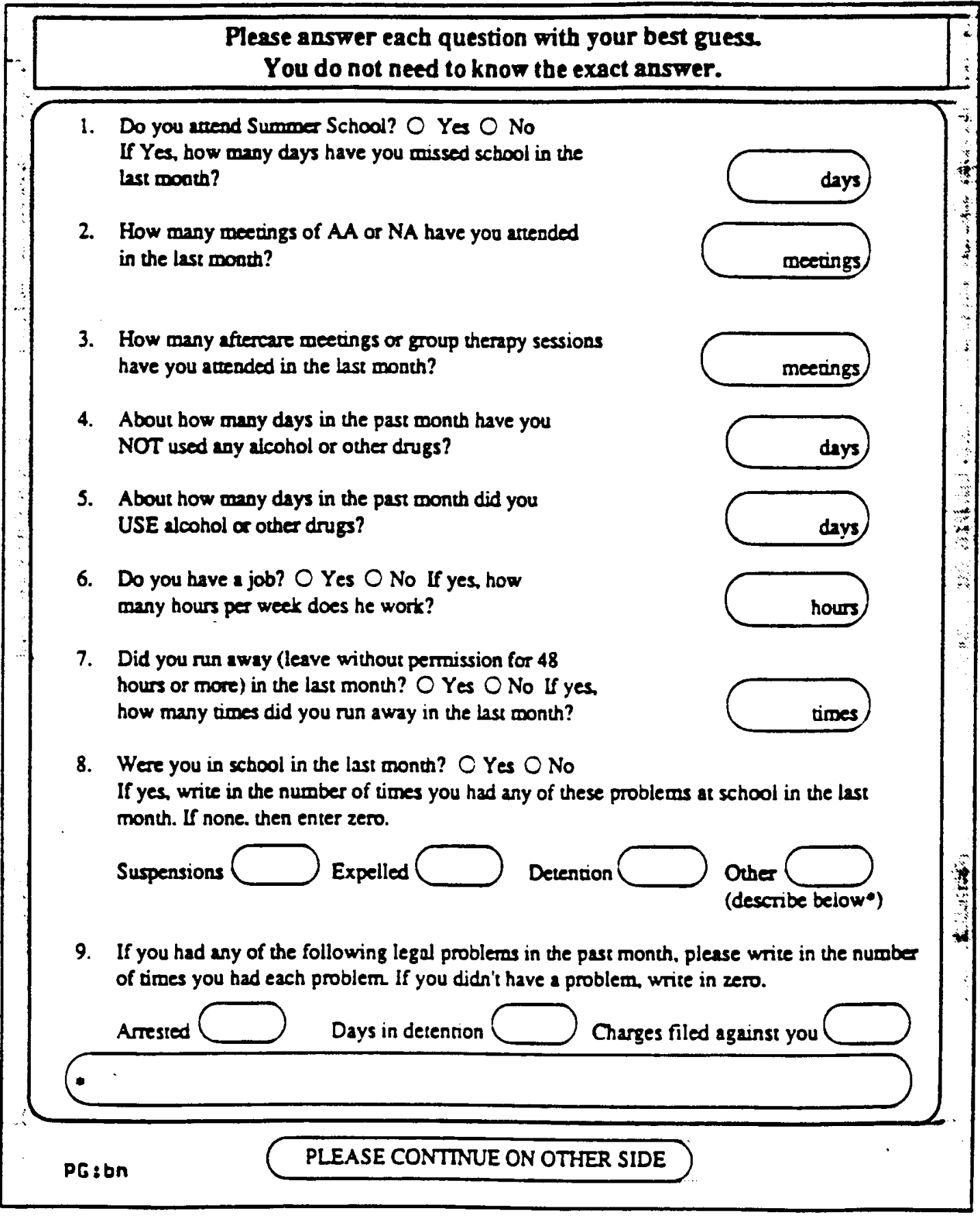




\section{PH.BASE: IHESIN ON GITIER SIDE:}

10. Have you been rehospitalized or placed in any other type of treatment facility sunce leaving our program? $O$ Yes $O$ No. If yes. please give the approximare dates of your placement or placemens below.

Name of Hospial or Faciliry

Approximate daces

11. Please use the scale below to show your level of PHYSICAL danger to yourself or others in the last month.

Intentional

SELF harm:

no thoughts
or statements
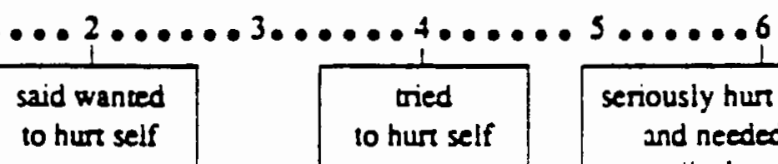

seriously hurr self and needed medical care

Intentional harm

10 OTHIERS:
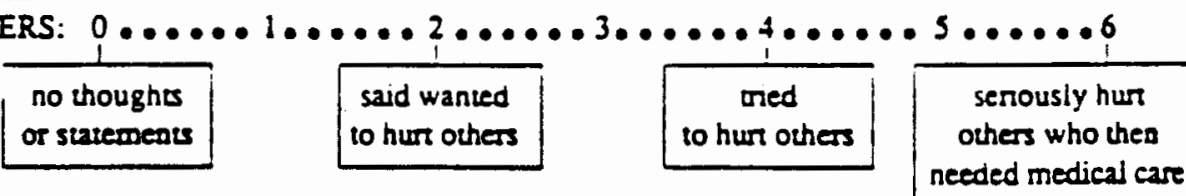
needed medical car

Please add any informasion you wish to give us about yourself below: 


\section{DO NOT PUT YOUR NAMIS (ON THIS PAPER ALLANSWERS WILL BE ANCNYYMOUS}

PLEASE USE THE SCALE BELOW TO RATE HOW WELL YOU ARE DOING, IN GENERAL, DURING THE PAST MONTH

please check the one BEST item in the list

10 NO problems. Doing well in school work and have a good social life.

9 Have problems SOMETIMES but otherwise do well in school, work and social life.

O 8 Have "everyday" worries or problems that sometimes get a little out of hand, but otherwise do OK in school, work \& social life.

O Generally OK, but have some problems like feeling down or not sleeping that interfere with school or social life.

O 6 Have some definite problems, like worrying a lot, being unhappy a lot, having few or now friends or being so active that you get on peoples' nerves.

O Have at least one serious problem like the following: talk about suicide, don't get along with other people, drink or use drugs a lot.

4 Have MAJOR problems which get in the way of work, family life or social life. For example: get into trouble a lot, talk strangely at times. don't always know what is going on, or have made a serious suicide attempt.

3 VERY CONFUSED. Hear voices and see things that aren't there.

Feel so confused that you can't relate to other people.

2 Want to hurt yourself or others all the time.

O Currently watched all the time so that you won't hurt yourself or other people. 
APPENDIX B

SAMPLE OP MAILING TO GUARDIANS 
Dear Family Member,

We at Pacific Gateway Hospital are in the process of gathering information which will help us to evaluate and improve the quality of our treatment program. Your participation will help us very much and it will also help people who come to the hopital in the future.

You can help us do this by filling out the attached questionnaire and returning it to us in the enclosed stamped envelope. There is also a consent form for you to sign indicating that you agree to participate in the study.

Peter Grover is a student at Portland state University and is helping us to gather and process this information as part of his master thesis project. If you have any questions about the questionnaire or the evaluation study you may reach him by calling the hospital at (503)-234-5353.

All information that you give will be kept strictly confidential. Please do not put your name on the questionnaire as it will be separated from the consent form when you return it so that no one handling the information will know the names of the people who give it.

It is also important for us to get information from your son or daughter about how they are doing now. If you agree to let them participate please sign the attached consent form and give him/her the questionnaire provided. We have also provided a separate envelope for them to send in their questionnaire. Please allow them to complete the questionnaire in private so that they can feel comfortable being honest.

Thank you for your help.

sincerely,

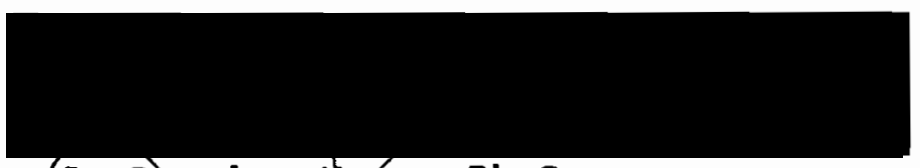

J. Douglas Myers Ph.D

Brogram Director

Adolescent Treatment Program 


\section{INFORMED CONSENI}

Note: 2 consent forms are attached. Please sign and return one form with the questionnaire. Detach the other form and keep for your records.

I, , hereby agree to serve as a subject in the Pacific Gateway Hospital treatment program outcome study conducted by Peter Grover under the supervision of Dr. Meyers (Facific Gateway Hospital) and Dr. Jones (Portland State University.) Iour responges will be used by Peter Grover as data in thesis for Portland State Oniversity's M.S. program in isychology.

I understand that the study involves filling out and returning the attached questionnaire.

I understand that by signing this consent form, I an releasing information from my son's/daughter's treatment records to Peter Grover for use as data in the above mentioned thesis.

Peter Grover agrees to answer any questions I ay have about the study and whet is expected of me. I bave been assured that all information I give will be kept confidential, and that the identity of all information used will remain anonymous.

I understand that the possible risks to we associated with this atudy are the inconvenience of filling out the questionnaire and the possible discomfort associated with answering some of the questions.

I understand that the purpose of this study is to find out more about what happens to people after they leave the progran so that we can find ways to improve the quality of the progran.

I way not recelve any direct benefit from participation in this study, but gy participation may belp to increase knowledge and benefit others in the future.

I understand that I a not required to be part of this study and that there will be no consequences if I do not participate.

I also give permission for my son/daughter or minor of whom I bave custody to take part in the atudy. I agree to provido hid/her with the questionnalre and consent forms included in this wailiag.

I have read and understand the above information.

Date

Signature

If you experience problems that are the result of your participation in this study, or if you wish to verify university approval of this study, please contact the secretary of the Human Subjects Research and Review Comittee, Office of Grants and Contracts, 303 Cramer Hall, Portland State Oniversity, 464-3417. 


\section{DO NOT PUT YOUR NAML ON THIS PAPER ALLANSWERS WILL BE ANONYMTOUS}

Please answer each question with your best guess.

You do not need to know the exact answer.

1. Does your daughter antend Summer School? O Yes $O$ No If Yes, how many days has she missed school in the last month?

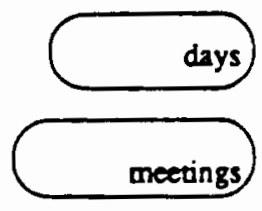

2. How many meetings of AA or NA has your daughter artended in the last month?

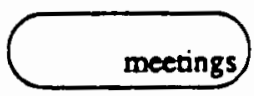

3. How many aftercare meetings or group therapy sessions has your daughter artended in the last month?

4. About how many days in the past moach bas your daughter NOT used any alcohol or other drugs?

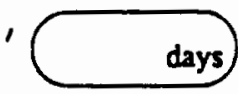

5. About how many days in the past month did your daughter USE alcohol or other drugs?

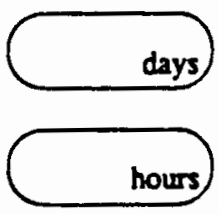

6. Does your daughter have a job? $\bigcirc$ Yes $\bigcirc$ No If yes, bow many hours per week does she wort?

7. Did your daughter run away (leave without perwission for $\mathbf{4 8}$ hours or more) in the last month? $O$ Yes $O$ No If yes, how many times did she run away in the last month?

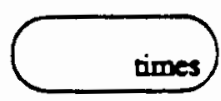

8. Was your daughter in school in the last month? $O$ Yes $O$ No If yes, write in the number of times she had any of these problerns at school in the last month. If none, then enter zero.

Suspensions

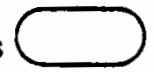
Expelled
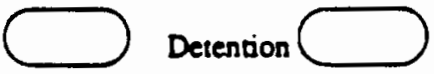

Other (describe below")

9. If your daughter had any of the following legal problems in the past month, please write in the number of times she had each probleon. If she didn't have a problem, write in zero.

Arrested $\bigcirc$ Days in detention $\square$ charges filed against her

PLEASE CONTINUE ON OTHER SIDE 


\section{PLFASE BSEIAY ON GTHFH SIDE}

10. Has your daughter been rehospitalized or placed in any other type of treatment facility since leaving our program? $\bigcirc$ Yes $\bigcirc$ No. If yes, please give the approximate dates of her placement or placements below.

Name of Hospital or Facility Approximate dates

11. Plesse use the scale below to show your daughter's level of PHYSICAL danger to himself or others in the last month.

Intentional

SELF harm:

$$
\begin{gathered}
\text { no thoughts } \\
\text { or statements } \\
\hline
\end{gathered}
$$
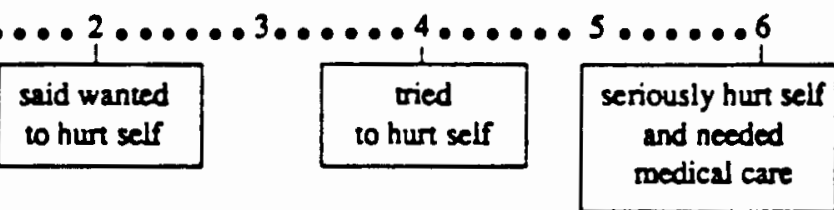

Intentional harm

to OTHERS: $0 \ldots \ldots \ldots 1$

no thoughts
or staterwents
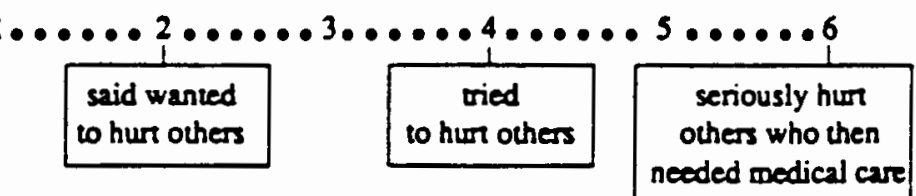

Please add any informacion you wish to give us about your daughter below: 


\section{DO NOT PUT YOUR NAML ON THIS PAPER ALLANSWBRS WIIL BE ANONYMTOUS}

\section{Please answer each question with your best guess. You do not need to know the exact answer.}

1. Does your daughter attend Surnmer School? $\bigcirc$ Yes $O$ No If Yes, how many days has she missed school in the last month?

2. How many meetings of AA or NA has your daughter attended in the last month?

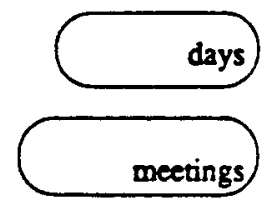

3. How many afiercare meetings or group therapy sessions has your daughter attended in the last month?

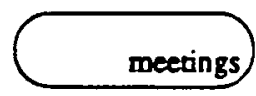

4. About how many days in the past month has your daughter NOT used any alcohol or other drugs?

5. About how many days in the past month did your daughter USE alcohol or other drugs?

6. Does your daughter have a job? $O$ Yes $O$ No If yes, how many hours per week does she work?
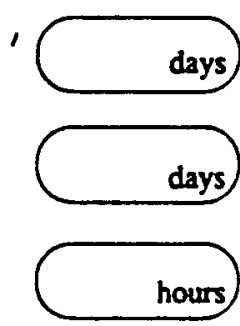

7. Did your daughter run away (leave without permission for $\mathbf{4 8}$ hours or more) in the last month? O Yes $O$ No If yes, how many times did she run away in the last month?

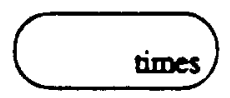

8. Was your daughter in school in the last month? $\bigcirc$ Yes $\bigcirc$ No If yes, write in the number of times she had any of these problems at school in the last month. If none, then enter zero.

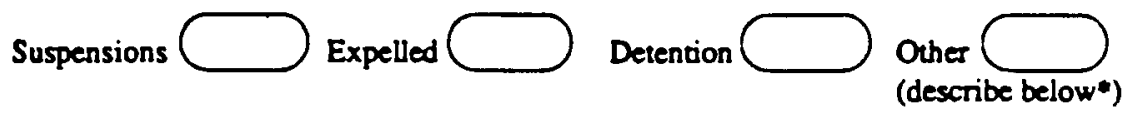

9. If your daughter had any of the following legal problems in the past month, please write in the number of times she had each problem. If she didn't have a problem, write in zero.

Arrested $\bigcirc$ Days in detention $\longrightarrow$ charges filed against her 


\section{PLFASE BEGIN ON CTHIRR SIDE}

10. Has your daughter been rehospitalized or placed in any other type of treatment facility since leaving our program? $O$ Yes $O$ No. If yes, please give the approximate dates of her placement or placements below.

Name of Hospital or Facility

11. Please use the scale below to show your daughter's level of PHYSICAL danger to himseif or others in the last month.

\section{Intentional}

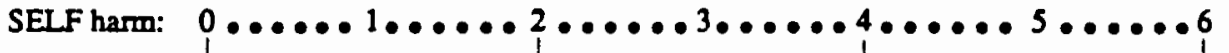
no thoughts
or statements said wanted to hurt self ried to hur self seriously hur self and needed medical care

Intentional harm to OTHERS:
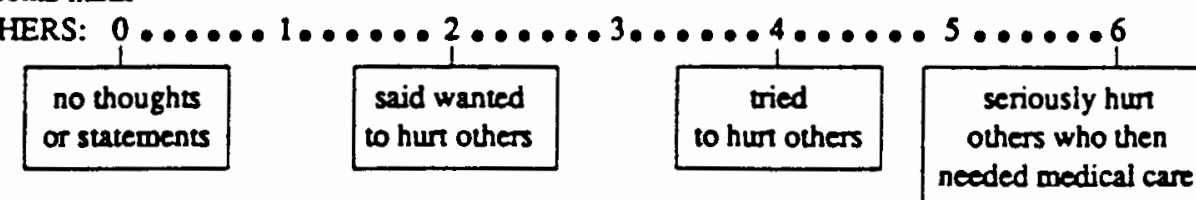

Please add any information you wish to give us about your daughter below: 


\section{DO NOT PUT YOUR NAMP ON THIS PAPER ALLANSWEERS WILL BE ANONYMOUS}

\begin{tabular}{|c|}
\hline $\begin{array}{l}\text { PLEASE USE THE SCALE BELOW TO RATE HOW WELL YOUR } \\
\text { DAUGHTER IS DOING, IN GENERAL, DURING THE PAST MONTH }\end{array}$ \\
\hline 10 please check the one BEST item in the list \\
\hline NO problems. Doing well in school work and has a good social life. \\
Has problems SOMETIMES but otherwise does well in school, work and \\
social life.
\end{tabular}

